Article

\title{
Evaluation of Color, Texture, Sensory and Antioxidant Properties of Gels Composed of Freeze-Dried Maqui Berries and Agave Sugar
}

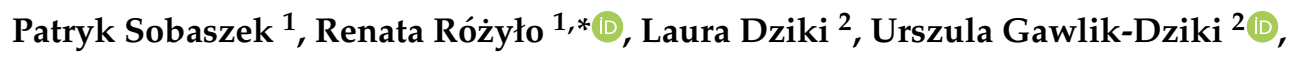 \\ Beata Biernacka $^{3}$ (D) and Marian Panasiewicz ${ }^{1}$ (D) \\ 1 Department of Food Engineering and Machines, University of Life Sciences in Lublin, 28 Głęboka Str., \\ 20-612 Lublin, Poland; patryk.sobaszek@gmail.com (P.S.); marian.panasiewicz@up.lublin.pl (M.P.) \\ 2 Department of Biochemistry and Food Chemistry, University of Life Sciences in Lublin,8 Skromna Str., \\ 20-704 Lublin, Poland; laura52757@gmail.com (L.D.); urszula.gawlik@up.lublin.pl (U.G.-D.) \\ 3 Department of Thermal Technology and Food Process Engineering, University of Life Sciences in Lublin, \\ 31 Głęboka Str., 20-704 Lublin, Poland; beata.biernacka@up.lublin.pl \\ * Correspondence: renata.rozylo@up.lublin.pl
}

Received: 18 September 2020; Accepted: 12 October 2020; Published: 16 October 2020

\begin{abstract}
The study aimed to determine the textural, sensory, and antioxidant properties of gels composed of maqui (Aristotelia chilensis) berries. These freeze-dried berries were tested in a powdered form as an additive ( $0-5 \%)$ to agave sugar (20\%) gels. Freeze-dried maqui powdered berries were dark purple to almost black in color and were characterized by an $L^{*}$ value of 16.3 , an $a^{*}$ value of 8.3, and $a b^{*}$ value of -9.6 . The $b^{*}$ values decreased from 11.8 to 2.3 with the increase in the amount of berry powder. There were no significant changes in the color of gels composed of berries at $4 \%$ and $5 \%$ concentration. Gels lost (almost twice) their hardness as the amount of maqui increased. The lowest values of hardness and the highest values of elasticity, springiness, gumminess, and chewiness were observed at $4 \%$ concentration of dried berries. The type of sugar did not affect the lightness of the gels ( $\mathrm{L}^{*}$ parameter) and the $\mathrm{a}^{*}$ value. The assessors evaluated the gels composed of agave sugar $(20 \%)$ and $4 \%$ maqui and $0.5 \%$ citric acid to be the best. Phenolic content and antioxidant activity were significantly higher in these gels compared to the control gels. After obtaining this low sugar gels, consumers could enrich their diets with healthier products.
\end{abstract}

Keywords: maqui; Aristotelia chilensis; agave; gels; texture; color

\section{Introduction}

In recent years, the awareness of maintaining a healthy lifestyle has greatly increased. As a result, consumers are paying more attention to the products they reach for, as additives used in food production have a detrimental effect on human health. Food producers are required to meet the demands of consumers to enable them to follow a healthy lifestyle [1,2]. Natural additives are preferred over synthetic ones as they not only have a positive effect on the properties of the product but can also have health-promoting effects [3].

Over the past 10 years, there is a significant increase in interest in berries and their potential health benefits. In particular, their phenolic components and expected health benefits have been recently studied in detail [4]. Maqui berries (Aristotelia chilensis) grow on evergreen shrubs or tree blooms in temperate forests from central to southern Chile, as well as western Argentina, where it was considered a weed by the local population [5]. The plant produces small edible purple-black berries measuring about $5 \mathrm{~mm}$ in diameter with one to six seeds. These berries are highly rich in anthocyanins, which provide intense blackish color and a high antioxidant content [6]. The small edible maqui purple and black 
berries and their leaves were used in Chilean medicine as an anti-hemorrhagic, anti-inflammatory, and antipyretic substance, as well as in treating heart disease and migraine. Chemical analysis suggests that maqui exhibits an anti-atherosclerotic effects [7]. Consumption of maqui was shown to provide health benefits, including anti-diabetic and anti-inflammatory effects, and linked with the treatment of Alzheimer's disease [6,8-10]. Consequently, the interest in maqui as a food dietary supplement to products has apparently increased. Although the A. chilensis berries are not still well known to people, owing to their very high concentration of antioxidants, these berries have hailed as a new superfruit [11]. Significant advantage of these berries is their high content of dolphinidine belonging to the group of anthocyanidins, which are known for their anti-inflammatory properties $[12,13]$.

Anthocyanins that have been identified in maquiare delphinidin 3-O-sambubioside-5-O-glucoside; delphinidin 3,5-O-diglucoside; cyanidin 3-O-sambubioside-5-O-glucoside; cyaniding 3,5-O-diglucoside; delphinidin 3-O-sambubioside; delphinidin 3-O-glucoside; cyaniding 3-O-glucoside, and cyanidin 3-O-sambubioside [14]. In addition, the main phenolic compounds that have been identified in these fruits are gallicacid, hexahydroxydiphenic acid, granatine B, punicacortein C, flavonols (myricetin, quercetin, kaempferol, and its derivatives) [15].

Nowadays, maqui berry extracts are available in the form of powder, liquid, or tablets. Tablets are a convenient form for everyday consumption, while powdered extracts can be used to make juices. Maqui fruit is slightly sour and refreshing; therefore, it is increasingly used in the production of sweets, jams, and drinks. It is also used by Araucanian people in the production of alcoholic beverages, such as liqueur or chicha, which are known as Tecu [16]. Due to the presence of anthocyanin pigments, the natural coloring properties of maqui fruit are also an advantage. In the Asyén region in Chile, an anthocyanin-rich natural dye has been obtained from purified maqui fruit, which is used in juices and drinks as well as in food, contributing to large export of these berries [7].

Owing to the aforementioned advantages of maqui berries, gels with maqui berries have been proposed. No articles about maqui gels have been found in the literature. For this reason, the maqui gels can be considered as innovation and have been considered the object of study of this work. Instead of beet sugar, agave sugar was added to those gels. Agave syrup obtained from the core of the plant has been used as a sweetener and a replacement for sugar or honey [17]. Agave belongs to the Agavaceae family, which includes over 300 species. It can store a large amount of juice due to the rapid uptake of available water from the ground and low losses of water during drought [18-20]. It also contains simple sugars and complex mixtures of fructo-oligosaccharides. Agave syrup tastes like corn syrup, and because it is unrefined, it contains other beneficial nutrients [21]. Agave fructans are used as sugar and fat for ice cream with reduced content of milk fat [22].

Due to the lack of research on the properties of gels composed of maqui berries with the addition of agave sugar, this work aimed to determine the textural, sensory, and antioxidant properties of these innovative gels.

\section{Materials and Methods}

\subsection{Chemicals}

Ferrozine (3-(2-pyridyl)-5, 6-bis-(4-phenyl-sulfonic acid)-1,2,4-triazine), ABTS (2,2'-azino-bis (3-ethylbenzthiazoline-6-sulphonic acid)), DPPH (1,1-diphenyl-2-picrylhydrazyl), Folin-Ciocalteau reagent, gallic acid and ammonium thiocyanate were purchased from Sigma-Aldrich company (Poznan, Poland). All others chemicals were of analytical grade.

\subsection{Materials}

Freeze-dried maqui berries (A. chilensis) (KenayAG, Kalisz, Poland) were sourced from Chile. According to the manufacturer's declaration, $100 \mathrm{~g}$ of the product contained $14.8 \mathrm{~g}$ of protein, $7.9 \mathrm{~g}$ of fat, and $70.3 \mathrm{~g}$ of carbohydrates, including $3.0 \mathrm{~g}$ of sugar and $36.4 \mathrm{~g}$ of fiber. The other ingredients were $9.1 \mathrm{mg}$ of sodium, $24.2 \mathrm{mg}$ of iron, $103.7 \mathrm{mg}$ of calcium, $0.175 \mathrm{mg}$ of vitamin A, and $8.6 \mathrm{mg}$ of vitamin 
C. Agave sugar (Intenson, Karczew, Poland), according to the manufacturer, contained $95 \%$ of organic sugar from agave and $5 \%$ maltodextrin and was characterized by a low glycemic index. Beet sugar (Polish sugar, KSC, Torun, Poland) contained 100\% of white sugar. Agar agar-natural gelling agent was sourced from Spain (Tar-Groch, Filipowice, Poland).

\subsection{Gel Formation}

In the first step of gel production, the amount of agar (gelling agent) to be added was determined by testing different levels: $0.5 \%, 1 \%, 1.5 \%$, and $2 \%$. This testing was done on pure aqueous $(80 \%)$ solutions with agave sugar $(20 \%)$. So far, the addition of sugar in gels has been studied up to $60 \%$ [23], however, due to the tendency to reduce the sugar content to 20\% (Sugar Reduction Program: Achieving the $20 \%, 2017$ [24]), such an additive was proposed in these studies. After boiling $\left(100{ }^{\circ} \mathrm{C}\right)$ the agave sugar solution, agar was added, and the mixture was boiled for another $10 \mathrm{~s}$. Then, the solution was cooled to $50{ }^{\circ} \mathrm{C}$, after which freeze-dried berries were added. Maqui berries in powder form were added in the amounts of $0 \%, 1 \%, 2 \%, 3 \%, 4 \%$, and $5 \%$.Gels composed of the optimal amount of berries $(4 \%)$ and agave sugar $(20 \%)$ were compared with gels composed of the same amount of berries $(4 \%)$ and beet sugar $(20 \%)$ and those composed of $0.5 \%$ citric acid. Citric acid is very often used in food recipes as acidity regulator. The optimal amount of citric acid to be added was determined in preliminary studies conducted in the range from $0 \%$ to $1.5 \%$. Only $0.5 \%$ of citric acid yielded satisfactory results, whereas $1 \%$ citric acid caused gel disintegration. The mixtures thus prepared were poured into silicone molds $(12 \mathrm{~cm} \times 4 \mathrm{~cm} \times 1.5 \mathrm{~cm})$ to a height of $1 \mathrm{~cm}$, where the samples were gelled at $21^{\circ} \mathrm{C}$. The gels were made in triplicate and tested $1 \mathrm{~h}$ after gelling.

\subsection{Color Analysis of Freeze-Dried Maqui Berries and Gels Obtained}

To examine the color of maqui fruit powder, a precise colorimeter WF30 (4Wave, Tychy, Poland) was used, which works in tandem with the CIE L* $a^{*} b^{*}$ and CIE LCH systems to determine the color of the raw materials tested $[25,26]$. The colorimeter was accompanied by a glass jar with a level marked $20 \mathrm{~mL}$ into which the powder was added. Parameter $\mathrm{L}^{*}$ on the colorimeter indicated the lightness of the color in the range from 0 to 100 . Parameter $\mathrm{a}^{*}$ displayed the negative (green) or positive (red) values in the range from -150 to +100 . The value of $b^{*}$ was also shown as either negative (blue) or positive (yellow) in the range from -100 to +150 .The parameter $C^{*}$ is defined as chroma and determines the color saturation which means the chromatic strength of an object color. The $h^{\circ}$ parameter determines the tone of the color. These measurements were carried out with a probe applied directly to the surface of the gels. $\mathrm{L}^{*}, \mathrm{a}^{*}, \mathrm{~b}^{*}, \mathrm{C}^{*}$, and $\mathrm{h}^{\circ}$ parameters were also determined for maqui berry powder. Based on three measurements, mean values and standard deviations were determined.

\subsection{Examination of the Gel Texture}

The texture assessment was based on the texture profile analysis (TPA) test [27], which involves compressing the gel samples to half their size (height $1 \mathrm{~cm}$, diameter $1.5 \mathrm{~cm}$ ). The TPA test was performed with a head equipped with a plug probe (diameter $30 \mathrm{~mm}$ ) of the Zwick Z020/TN2 (Zwick Roell, Ulm, Germany) machine moving at a speed of $1 \mathrm{~mm} \cdot \mathrm{s}^{-1}$, with compression up to $25 \%$ of the sample height. Based on these measurements, charts displaying force values and displacement of the capital, were obtained, which were used for determining the gel hardness, elasticity, cohesiveness, springiness, and chewiness. Hardness $(\mathrm{N})$ was expressed by the maximum force on the first peak. On the other hand, elasticity $(\mathrm{mm})$ was expressed by the width of the second peak. Springiness was determined as the ratio of the width of the second and the first measurement. Cohesiveness was expressed by the quotient of the surface area under the first peak A1 and under the second peak A2. To calculate the gumminess $(\mathrm{N})$, the values of hardness and cohesiveness were multiplied, and to obtain chewiness $(\mathrm{N})$, the gumminess and springiness were multiplied. All the measurements were made ten times for each of the tests. 


\subsection{Evaluation of $p H$ Value of Gels}

The $\mathrm{pH}$ value was measured before the gelation process ended with the aid of a Testo 206-ph2 (Testo, Pruszków, Poland) pH meter, which includes a temperature sensor enabling the simultaneous measurement of $\mathrm{pH}$ and temperature. Before starting the measurements, the $\mathrm{pH}$ meter was calibrated at two measuring points using buffer solutions.

\subsection{Organoleptic Gel Evaluation}

The organoleptic examination of the gels (height $1 \mathrm{~cm}$, diameter $1.5 \mathrm{~cm}$ ) was carried out by 68 trained assessors on a 9-point hedonic scale, where 1 represented "dislike extremely," 5 indicated neither like nor dislike, and 9 represented "like extremely" [28]. After testing each gel, the assessors rinsed their mouths with water and then recorded the points.

\subsection{Total Phenolic Content}

The total phenolic content (TPC) was determined by performing solvent extraction of the raw material (freeze-dried maqui powder) and fresh gel samples. One gram of sample was extracted twice with a $5 \mathrm{~mL}$ mixture of methanol and water $(1: 1, v / v, 30 \mathrm{~min})$, and centrifuged at 10,000 rpm for $15 \mathrm{~min}$. Extraction procedure was repeated twice, the supernatants were combined [29,30]. Following this, the extracts were stored in darkness at $-20{ }^{\circ} \mathrm{C}$. TPC was determined with the Folin-Ciocalteu method [31]. For this purpose, the extract sample $(0.1 \mathrm{~mL})$ was mixed with distilled water $(0.1 \mathrm{~mL})$ and Folin's reagent $(0.4 \mathrm{~mL})\left(1: 5 \mathrm{H}_{2} \mathrm{O}\right)$, to which $10 \% \mathrm{Na}_{2} \mathrm{CO}_{3}(2 \mathrm{~mL})$ was added. TPC was expressed in milligrams as gallic acid equivalents (GAE) after measuring the absorbance of the mixtures on a spectrophotometer $(720 \mathrm{~nm})$. The solution was mixed thoroughly, and then held in darkness for $30 \mathrm{~min}$ at ambient temperature. After incubation, the absorbance at $725 \mathrm{~nm}$ was measured. Total phenolic content was calculated as mg of gallic acid equivalents/g dry weight (mg GAE/g DW), using a gallic acid calibration curve (range, $0-500 \mu \mathrm{g} / \mathrm{mL}$, using curve equation $y=0.0034 \cdot x+0.0038, R^{2}=0.9947$ ).

\subsection{Antioxidant Activity}

\subsubsection{Ability to Quench ABTS Radicals}

The ABTS radical scavenging activity was determined according to [32], with some modifications. The ability of samples to quench the ABTS free radical was assessed according to the following equation:

$$
\text { scavenging } \%=[(A C-A A) / A C)] \times 100 \text {, }
$$

where $A C$ is the absorbance of the control and $A A$ is the absorbance of the sample.

The half-maximal inhibitory concentration $\mathrm{EC}_{50}$ value was determined by interpolation of the dose-response curves. The $\mathrm{EC}_{50}$ values were calculated at fitted models as the concentration of the tested compound gave $50 \%$ of the maximum inhibition based on a dose-dependent mode of action. A lower $\mathrm{EC}_{50}$ value indicated a higher antioxidant activity.

\subsubsection{Ability to Quench DPPH Radicals}

Antiradical activity against DPPH $\bullet$ was determined using the method proposed by Brand-Williams, Cuvelier, and Berset [33]. The ability of samples to quench the DPPH free radical was assessed according to the following equation:

$$
\text { scavenging } \%=[(A C-A A) / A C)] \times 100,
$$

where $A C$ is the absorbance of the control and $A A$ is the absorbance of the sample.

The half-maximal inhibitory concentration $\mathrm{EC}_{50}$ value was determined by interpolation of the dose-response curves. The $\mathrm{EC}_{50}$ values were calculated at fitted models as the concentration of the 
tested compound gave $50 \%$ of the maximum inhibition based on a dose-dependent mode of action. A lower $\mathrm{EC}_{50}$ value indicated a higher antioxidant activity.

\subsubsection{Ferric Reducing Power (FRAP)}

Reducing power was determined according to [34]. A total of $500 \mu \mathrm{L}$ of $200 \mathrm{mM}$ phosphate buffered saline extract and $500 \mu \mathrm{L}$ of a $1 \%$ solution of potassium ferri-cyanide were added to $500 \mu \mathrm{L}$ of the extract. The prepared mixture was insulated at $50{ }^{\circ} \mathrm{C}$ for $20 \mathrm{~min}$. Then, $500 \mu \mathrm{L}$ of $10 \%$ trichloroacetic acid (TCA) was added and the mixture was rested for few minutes. Following this, $1 \mathrm{~mL}$ of that mixture was taken and mixed with $1 \mathrm{~mL}$ of deionized water and $0.2 \mathrm{mLof} 1 \%$ iron (II) chloride. Absorbance was measured at $725 \mathrm{~nm}$. Reducing power determined as $\mathrm{EC}_{50}$ was the effective concentration at which the absorbance was 0.5 for reducing power and was obtained by interpolation from linear regression analysis.

\subsubsection{Metal Chelating Activity (CHEL)}

Chelating power was determined by the method of [35]. The chelating potential was assessed according to the formula:

$$
\% \text { inhibition }=[1-(A s / A c)] \times 100,
$$

where $A c$ is the absorbance of the control and $A s$ is the absorbance of the sample.

Antioxidant activity was determined as $\mathrm{EC}_{50}$ - extract concentration providing $50 \%$ of activity was based on a dose-dependent mode of action. A lower $\mathrm{EC}_{50}$ value indicated a higher antioxidant activity.

\subsection{Statistical Analysis}

Statistical analysis was performed at a significance level of $\alpha=0.05$ using statistical software (Statistica 6 PL, Statsoft Polska, Cracow, Poland, 2001). The data were analyzed using the analysis of variance, and the means were compared using Tukey's range test.

\section{Results and Discussion}

\subsection{Color Values of Freeze-Dried Maqui Berries and Gels Obtained}

Freeze-dried maqui berries were characterized by an $L^{*}$ value of 16.33 , an $a^{*}$ value of 8.28 , a b* value of -9.57 , a $C^{*}$ value of 12.65 , and a $h^{\circ}$ value of 49.14 (Table 1 ). Apparently, the berries had a dark purple-red color. 
Table 1. Color parameters of maqui powder and analyzed gels.

\begin{tabular}{|c|c|c|c|c|c|c|}
\hline \multirow{2}{*}{\multicolumn{2}{|c|}{ Type of Sample }} & \multicolumn{5}{|c|}{ Color Parameters } \\
\hline & & $\mathrm{L}^{*}$ & $a^{*}$ & $\mathbf{b}^{*}$ & $\mathrm{C}^{*}$ & $\mathbf{h}^{\circ}$ \\
\hline \multicolumn{2}{|c|}{ Maqui Powder } & $16.33 \pm 0.33^{a}$ & $8.28 \pm 0.10^{\mathrm{d}}$ & $9.57 \pm 0.244^{\mathrm{e}}$ & $12.65 \pm 0.24 \mathrm{~d}, \mathrm{e}$ & $49.14 \pm 0.46^{\mathrm{g}}$ \\
\hline \multirow{4}{*}{ Amount of agar } & $0.5 \%$ & $55.12 \pm 0.81^{\mathrm{g}}$ & $2.0 \pm 0.12^{a}$ & $12.05 \pm 0.70^{\mathrm{f}}$ & $13.15 \pm 0.92^{\mathrm{e}}$ & $81.99 \pm 1.21^{\mathrm{j}}$ \\
\hline & $1 \%$ & $54.28 \pm 0.57^{\mathrm{f}, \mathrm{g}}$ & $2.11 \pm 0.17^{\mathrm{a}, \mathrm{b}}$ & $11.97 \pm 0.69^{f}$ & $12.94 \pm 0.85^{\mathrm{d}, \mathrm{e}}$ & $80.19 \pm 0.81^{i, j}$ \\
\hline & $1.5 \%$ & $53.39 \pm 0.88^{f, g}$ & $2.33 \pm 0.29^{a, b}$ & $11.85 \pm 0.56^{\mathrm{f}}$ & $12.07 \pm 0.61^{\mathrm{d}}$ & $78.89 \pm 0.91{ }^{\mathrm{i}}$ \\
\hline & $2 \%$ & $52.09 \pm 0.73^{\mathrm{f}}$ & $2.41 \pm 0.11^{\mathrm{b}}$ & $11.71 \pm 0.62^{f}$ & $11.13 \pm 0.78^{c, d}$ & $75.32 \pm 1.11^{\mathrm{h}}$ \\
\hline \multirow{6}{*}{ Amount of maqui } & $0 \%$ & $53.04 \pm 0.58^{f}$ & $2.33 \pm 0.29^{a, b}$ & $11.85 \pm 0.56^{f}$ & $12.07 \pm 0.61^{\mathrm{d}}$ & $78.89 \pm 0.91^{\mathrm{i}}$ \\
\hline & $1 \%$ & $27.16 \pm 0.31 \mathrm{~d}, \mathrm{e}$ & $4.13 \pm 0.16^{c}$ & $3.67 \pm 0.89^{b, c}$ & $5.56 \pm 0.49^{a}$ & $41.18 \pm 1.91^{f}$ \\
\hline & $2 \%$ & $26 \pm 0.68^{\mathrm{d}}$ & $7.87 \pm 0.42^{d}$ & $5.58 \pm 0.35^{\mathrm{d}}$ & $9.66 \pm 0.94^{b}$ & $37.78 \pm 1.3^{\mathrm{e}}$ \\
\hline & $3 \%$ & $24.29 \pm 0.22^{c}$ & $10.43 \pm 0.21 \mathrm{e}^{\mathrm{e}}$ & $4.46 \pm 0.39^{c}$ & $11.35 \pm 0.35^{\mathrm{c}, \mathrm{d}}$ & $23.13 \pm 1.43^{c}$ \\
\hline & $4 \%$ & $22.86 \pm 0.39^{b}$ & $10.91 \pm 0.23^{\mathrm{e}, \mathrm{f}}$ & $2.52 \pm 0.22^{\mathrm{a}}$ & $11.19 \pm 0.20^{c, d}$ & $13.34 \pm 0.87^{\mathrm{a}}$ \\
\hline & $5 \%$ & $22.12 \pm 0.48^{b}$ & $10.99 \pm 0.32^{\mathrm{e}, \mathrm{f}}$ & $2.32 \pm 0.24^{\mathrm{a}}$ & $11.02 \pm 0.31^{b, c}$ & $12.44 \pm 0.99^{\mathrm{a}}$ \\
\hline \multirow{3}{*}{ Optimal gels } & Ag4M0C & $22.86 \pm 0.39^{b}$ & $10.91 \pm 0.23^{\mathrm{e}, \mathrm{f}}$ & $2.52 \pm 0.22^{a}$ & $11.19 \pm 0.2^{c}$ & $13.34 \pm 0.87^{\mathrm{a}}$ \\
\hline & Ag4M0.5C & $28.91 \pm 0.16^{\mathrm{e}}$ & $10.5 \pm 0.59 \mathrm{e}, \mathrm{f}$ & $6.09 \pm 0.48^{d}$ & $12.16 \pm 0.67^{\mathrm{d}, \mathrm{e}}$ & $30.24 \pm 1.35^{\mathrm{d}}$ \\
\hline & B4M0C & $23.24 \pm 0.33^{b}$ & $11.03 \pm 0.19^{f}$ & $3.14 \pm 0.15^{b}$ & $11.46 \pm 0.22^{c, d}$ & $15.89 \pm 0.46^{b}$ \\
\hline
\end{tabular}

$\mathrm{a}-\mathrm{j}$, Means with different letter in the same column are significantly different $(\alpha<0.05)$. Ag4M0C-agave sugar gel with $4 \%$ maqui powder and $0 \%$ citric acid, Ag4M0.5C - agave sugar gel with $4 \%$ maqui powder and $0.5 \%$ citric acid, B4M0C - beet sugar gel with $4 \%$ maqui and $0 \%$ citric acid.

Freeze-dried powders of maqui berries obtained by Casati et al. [36] were also characterized by a dark color. In other studies $[37,38]$, maqui powders obtained from extract with spray drying exhibited a vivid purple color and were therefore much lighter than those obtained from whole berries using freeze-drying.

The purple-red color is often attributable to the high anthocyanin content, which has been proven in many studies on maqui berries [38-40].

In the first stage of the study, pure gels were tested to determine the optimal amount of agar added. No significant differences were observed for the color parameters (Table 1). The brightness value, $L^{*}$, shows the darkest black at $L^{*}=0$ and the brightest white at $L^{*}=100$. The $a^{*}$ and $b^{*}$ values represent true neutral gray values at $a^{*}=0$ and $b^{*}=0$. The $a^{*}$ parameter ranges from -150 to +100 . Negative values of this parameter show the share of green, and positive values-red. Whereas the $b^{*}$ parameter ranges from -100 to +150 , and negative values show the strength of blue and positive values of yellow. When a variable amount of freeze-dried maqui berries was added, significant changes were observed with $1 \%$ addition, as well as with subsequent addition of berries. Gels with $1 \%$ and $2 \%$ maqui powder had a low color saturation value $\left(C^{*}\right)$. With the $3 \%$ addition, the saturation was similar to that of the 4 and $5 \%$. The color tone $\left(\mathrm{h}^{\circ}\right)$ did not differ for the samples with $4 \%$ and $5 \%$ maqui powder. There were no significant changes in the color of gels composed of $4 \%$ and $5 \%$ concentrations of maqui berries. The value of the $\mathrm{a}^{*}$ index was the lowest in the control gel, which gradually increased with the amount of freeze-dried berry powder and was nearly five times higher with $4 \%$ berry concentration. Each of the measured values was above 0 , which indicated the red content. The main thing was to maximize the variable $\mathrm{a}^{*}$ because this indicates how red the sample is and it usually relates to anhocyanins content. The red content in gels is due to the color of the fruit, which often changes from red to purple-red during ripening. As noted earlier, the freeze-dried powders exhibited a dark purple-red color [39]. In addition, maqui berries are a particularly rich source of anthocyanins, which are a group of red, purple, violet, and blue water-soluble polyphenolic pigments [41]. Another research showed that lemon juice enriched with maqui berries showed a red color [42]. Similarly, significant red staining was observed in isotonic beverages [43]. The values of the $b^{*}$ parameter decreased with the increased addition of the A. chilensis berry, showing an almost four fold difference between the control sample (11.8) and the sample with $4 \%$ content of maqui fruit (2.52). A decrease in the value of the $b^{*}$ index indicates a greater proportion of blue than yellow content. Anthocyanin pigments, in addition to the 
red group, are composed of blue and violet water-soluble polyphenolic components that are available in berries [44].

Gels composed of an optimal amount of maqui berries (4\%) and agave sugar (20\%) (Ag4M0C) were compared with those composed of maqui berries (4\%) and beet sugar (20\%) (B4M0C) as well as against those composed of citric acid (Ag4M0.5C) (Table 1). It was noticed that the type of sugar did not affect the lightness ( $\mathrm{L}^{*}$ parameter) (22.9 for Ag4M0C and 23.2 for B4M0C) and the $\mathrm{a}^{*}$ value of the gels composed of citric acid (10.9 for Ag4M0C and 10.5 for Ag4M0.5C). On the contrary, the value of the $b^{*}$ parameter was more than twice the value measured for gels composed of maqui berries and citric acid (Ag4M0.5C) (6.1) when compared to acid-free maqui berry gels composed of beet sugar and agave sugar (B4M0C; Ag4M0C) $(3.1 ; 2.5)$. The gels composed of citric acid were lighter in color and exhibited more yellow than blue content. This clearly shows that anthocyanin pigments change color due to acidity [42,45].

In our study, the highest $\mathrm{pH}$ value was found in the gels composed of beet sugar (B4M0C) $(\mathrm{pH}=8.0)$; the replacement of this sugar with agave sugar (Ag4M0C) slightly reduced the $\mathrm{pH}$ parameter $(\mathrm{pH}=7.8)$, while the addition of $0.5 \%$ citric acid significantly reduced the $\mathrm{pH}$ value to 7.5 .

\subsection{Texture of Gels with Maqui Berries}

The texture of the clear gels changed significantly with the amount of agar used (Table 2). With an increase in the amount of agar in the range from $0.5 \%$ to $1.5 \%$, the hardness, elasticity, and springiness of the gels significantly increased. With a $2 \%$ concentration of agar, the cohesiveness, chewiness, and gumminess of the gels decreased significantly; therefore, the $1.5 \%$ concentration was considered optimal. The cohesiveness of gels increased only with an additive amount of up to $1.5 \%$, whereas further addition resulted in gel breaking. Similarly, in another study, the elasticity of gelatin gels was significantly affected by the concentration of gelatin. The authors obtained highly concentrated gels with a higher concentration of gelatin [46].

Table 2. Textural parameters of analyzed gels.

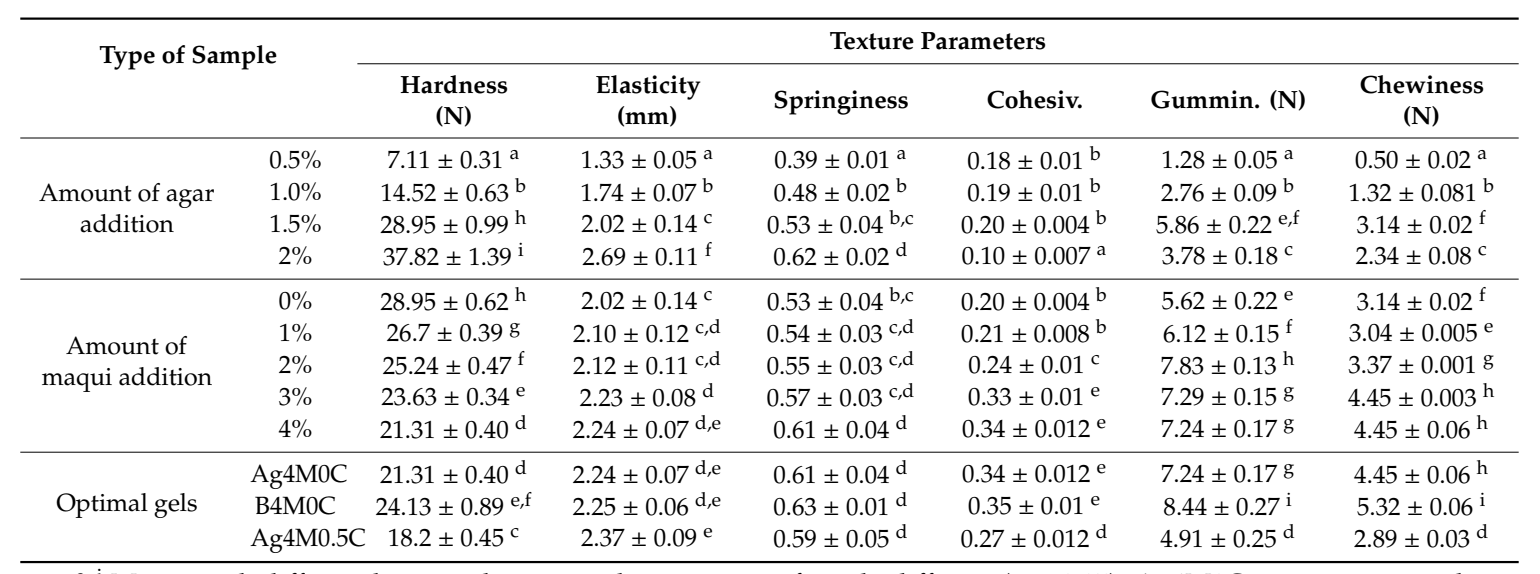

${ }^{a-i}$ Means with different letter in the same column are significantly different $(\alpha<0.05)$. Ag4M0C-agave sugar gel with $4 \%$ maqui powder and $0 \%$ citric acid, Ag4M0.5C-agave sugar gel with $4 \%$ maqui powder and $0.5 \%$ citric acid, B4M0C-beet sugar gel with $4 \%$ maqui and $0 \%$ citric acid.

Based on above mentioned textural parameters, $1.5 \%$ was determined as the optimal amount of agar, which was used in further stages of the research. The gels lost their hardness as the amount of maqui increased. The difference between the control gel and the gels with different berry compositions was significant. The highest values of chewiness, cohesiveness, springiness, and elasticity were obtained at $4 \%$ concentration of dried berries. When comparing gels composed of the optimal amount of maqui (4\%) and with agave sugar (20\%) (Ag4M0C), beet sugar $(20 \%)$ (B4M0C), and citric acid $(0.5 \%)(\mathrm{Ag} 4 \mathrm{M} 0.5 \mathrm{C})$, the highest values of hardness, cohesiveness, chewiness, and gumminess were observed for gels composed of beet sugar, whereas gels composed of citric acid exhibited the lowest 
values of these parameters. Other authors showed that the rheological properties of gelatin gels were independent of $\mathrm{pH}$ in the range of 4.6-8.0. At lower $\mathrm{pH}$, gelation of gelatin was significantly inhibited [46].

\subsection{Sensory Evaluation of Gels with Maqui Berries}

The variable addition of maqui berries resulted in favorable sensory changes. The gels with the highest concentration of berries were darker in color and had the best taste. The powder darkens the color of the gels making them more attractive and adds a sour aftertaste [47]. According to Freses and Paz [48], the colors of many berry varieties can be attributed to their anthocyanin content; the higher the anthocyanin content, the darker the fruit is.

The gels composed of citric acid $(0.5 \%)$ and maqui powder $(4 \%)$ attained the highest scores; the gels with dark purple color turned purple-red and tasted and smelled stronger than the other varieties. Citric acid gels exhibited a slightly sour taste, which had a positive effect on their assessment by the evaluators (Figure 1).
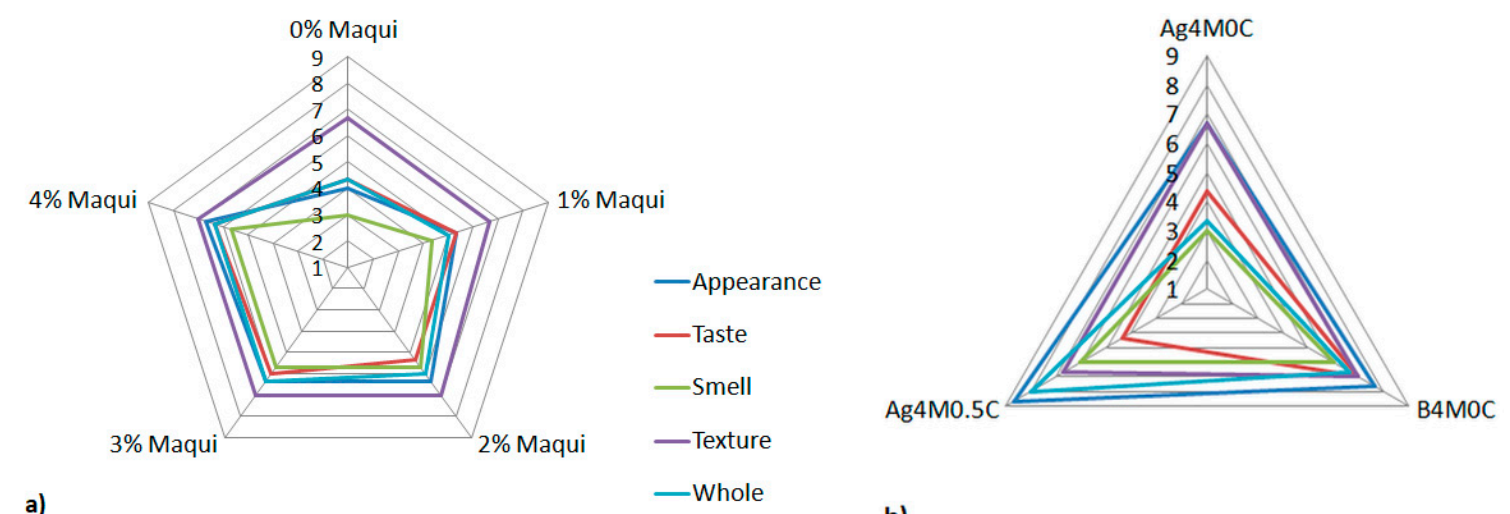

a)

b)

Figure 1. Organoleptic assessment of gels, (a) comparison of gels composed of varying contents of maqui berries; (b) comparison of gels composed of agave sugar, regular sugar, and citric acid. Ag4M0C - agave sugar gel with $4 \%$ maqui powder and $\%$ citric acid, Ag4M0.5C - agave sugar gel with $4 \%$ maqui powder and $0.5 \%$ citric acid, B4MOC—-beet sugar gel with $4 \%$ maqui and $0 \%$ citric acid.

\subsection{Total Phenolic Content and Antioxidant Activity of Gels with Maqui Berries}

Maqui freeze-dried powder used for gel formation was characterized by a high TPC of 34.82 GAE $\mathrm{mg} / \mathrm{g}$. In previous research, crude extract from fresh berries was found to be an important source of polyphenolic compounds, with a TPC of $45.7 \mathrm{mg} \mathrm{GAE} / \mathrm{g}$ [7]. Another research also confirmed the high polyphenol content as well as widely varying concentrations of anthocyanins and flavonols in maqui berries [48]. TheTPC and the antioxidant activity of the gels composed of maqui and agave sugar (Ag4M0C) were significantly higher compared to the gels composed of beet sugar (B4M0C). In addition, the control gels without maqui berries did not exhibit any antioxidant activity. The addition of citric acid had a positive impact on the antioxidant activity measured by ABTS and did not significantly change the DPPH parameter. However, it should be noted that the CHEL value do differ significantly in Table 3. The highest antioxidant activity measured by means of FRAP was found in agave sugar gels and those with a $4 \%$ concentration of maqui berries without citric acid. The addition of maqui berries increases the content of phenols, which contributes to the antioxidant capacity [47]. 
Table 3. Antioxidant properties of maqui powder and gels with the optimal amount* of maqui powder.

\begin{tabular}{|c|c|c|c|c|c|}
\hline $\begin{array}{l}\text { Kind of } \\
\text { Sample }\end{array}$ & $\begin{array}{c}\text { TPC } \\
\text { (GAEmg/g) }\end{array}$ & $\begin{array}{c}\text { ABTS } \\
\left(\mathrm{EC}_{50} \mathrm{mg} / \mathrm{mL}\right)\end{array}$ & $\begin{array}{c}\text { DPPH } \\
\left(\mathrm{EC}_{50} \mathrm{mg} / \mathrm{mL}\right)\end{array}$ & $\begin{array}{c}\text { CHEL } \\
\left(\mathrm{EC}_{50} \mathrm{mg} / \mathrm{mL}\right)\end{array}$ & $\begin{array}{c}\text { FRAP } \\
\left(\mathrm{EC}_{50} \mathrm{mg} / \mathrm{mL}\right)\end{array}$ \\
\hline Maqui powder & $34.82 \pm 2.18^{\mathrm{d}}$ & $1.37 \pm 0.03^{\mathrm{a}}$ & $3.38 \pm 0.23^{a}$ & $28.42 \pm 1.67^{\mathrm{a}}$ & $2.48 \pm 0.02^{\mathrm{a}}$ \\
\hline Ag4M0C & $1.92 \pm 0.10^{c}$ & $27.60 \pm 0.65^{d}$ & $60.93 \pm 4.34^{b}$ & $196.60 \pm 3.34^{b}$ & $31.59 \pm 0.10^{b}$ \\
\hline $\mathrm{Ag} 4 \mathrm{M} 0.5 \mathrm{C}$ & $1.87 \pm 0.10^{b}$ & $22.60 \pm 0.10^{b}$ & $58.86 \pm 3.93^{b}$ & $208.99 \pm 4.78^{c}$ & $45.00 \pm 1.42^{c}$ \\
\hline B4M0C & $1.62 \pm 0.06^{\mathrm{a}}$ & $25.14 \pm 0.09^{c}$ & $65.61 \pm 7.05^{c}$ & $189.00 \pm 4.17^{b}$ & $50.48 \pm 0.94^{d}$ \\
\hline
\end{tabular}

\section{Conclusions}

The freeze-dried maqui berries in the powdered form were characterized by a dark purple-red color; therefore, their addition at $1 \%$ concentration caused a significant change in the color of the gels. The $4 \%$ concentration of maqui berries was found to be the most optimal. The texture of the gels significantly changed with the amount of agar (geling agent) addition from $0.5 \%$ to $2.0 \%$. Increasing the concentration of agar increased the hardness, springiness, and elasticity of the gels. With a $2 \%$ concentration of agar, the cohesiveness, chewiness, and gumminess of the gels decreased significantly; therefore, the $1.5 \%$ concentration was considered optimal. The addition of maqui berries at a concentration from $0 \%$ to $4 \%$ caused a slight but significant decrease in the hardness of gels, while their springiness, elasticity, and cohesiveness increased. Replacing beet sugar with agave sugar and the addition of citric acid at $0.5 \%$ concentration had a positive effect on the antioxidant activity (ABTS and DPPH) of gels. In these studies, innovative and healthy gels with a reduced (20\%) sugar content from agave were developed. Gels were characterized by an increased content of antioxidants, thanks to the addition of freeze-dried maqui powder (4\%). In addition, the gels were characterized by improved red color and whole acceptability thanks to the acidity regulation by $0.5 \%$ addition of citric acid.

Author Contributions: Conceptualization, P.S. and R.R.; methodology, R.R. and U.G.-D.; software, L.D., U.G.-D. and B.B.; validation, M.P.; formal analysis, P.S. and R.R.; investigation, P.S., L.D. and U.G.-D. resources, P.S. and R.R.; data curation, L.D. and U.G.-D.; writing - original draft preparation, P.S. and R.R.; writing-review and editing, R.R. and B.B.; visualization, B.B.; supervision, M.P.; project administration, R.R.; funding acquisition, R.R. and U.G.-D. All authors have read and agreed to the published version of the manuscript.

Funding: This research received no external funding.

Conflicts of Interest: The authors declare no conflict of interest.

\section{References}

1. Ditlevsen, K.; Sandøe, P.; Lassen, J. Healthy food is nutritious, but organic food is healthy because it is pure: The negotiation of healthy food choices by Danish consumers of organic food. Food Qual. Pref. 2019, 71, 46-53. [CrossRef]

2. Vasileska, A.; Rechkoska, G. Global and Regional Food Consumption Patterns and Trends. Procedia Soc. Behav. Sci. 2012, 44, 363-369. [CrossRef]

3. Carocho, M.; Morales, P.; Ferreira, I.C.F.R. Natural food additives: Quo vadis? Trends Food Sci. Technol. 2015, 45, 284-295. [CrossRef]

4. Wu, X.; Gu, L.; Prior, R.L.; McKay, S. Characterization of anthocyanins and proanthocyanidins in some cultivars of Ribes, Aronia, and Sambucus and their antioxidant capacity. J. Agric. Food Chem. 2004, 52, 7846-7856. [CrossRef] [PubMed]

5. Dirnböck, T.; Greimler, P.; Lopez, P.; Stuessy, T.F. Predicting Future Threats to the Native Vegetation of Robinson Crusoe Island, Juan Fernandez Archipelago, Chile. Conserv. Biol. 2003, 17, 1650-1659. [CrossRef] 
6. Miranda-Rottmann, S.; Aspillaga, A.A.; Pérez, D.D.; Vasquez, L.; Martinez, A.L.; Leighton, F. Juice and phenolic fractions of the berry Aristoteliachilensis inhibit LDL oxidation in vitro and protect human endothelial cells against oxidative stress. J. Agric. Food Chem. 2002, 50, 7542-7547. [CrossRef]

7. Rubilar, M.; Jara, C.; Poo, Y.; Acevedo, F.; Gutierrez, C.; Sinerio, J.; Shene, C. Extracts of Maqui (Aristoteliachilensis) and Murta (UgnimolinaeTurcz.): Sources of Antioxidant Compounds and r-Glucosidase/r-Amylase Inhibitors. J. Agric. Food Chem. 2011, 59, 1630-1637. [CrossRef]

8. Céspedes-Acuña, C.L.; El-Hafidi, M.; Pavon, N.; Alarcon, J. Antioxidant and cardioprotective activities of phenolic extracts from fruits of Chilean blackberry Aristoteliachilensis (Elaeocarpaceae), Maqui. Food Chem. 2008, 107, 820-829. [CrossRef]

9. Rojo, L.E.; Ribnicky, D.; Logendra, S.; Poulev, A.; Rojas-Silva, P.; Kuhn, P.; Dorn, R.; Grace, M.H.; Lila, M.A.; Raskin, I. In vitro and in vivo anti-diabetic effects of anthocyanins from Maqui Berry (Aristoteliachilensis). Food Chem. 2012, 131, 387-396. [CrossRef]

10. Schreckinger, M.E.; Wang, J.; Yousef, G.; Lila, M.A.; Gonzalez de Mejia, E. Antioxidant capacity and in vitro inhibition of adipogenesis and inflammation by phenolic extracts of Vacciniumfloribundum and Aristoteliachilensis. J. Agric. Food Chem. 2010, 58, 8966-8976. [CrossRef]

11. Escribano-Bailón, M.T.; Alcalde-Neon, C.; Muñoz, O.; Rivas-Gonzalo, J.C.; Santos-Buelga, C. Anthocyanins in berries of Maqui [Aristoteliachilensis (Mol.) Stuntz]. Phytochem. Anal. 2006, 17, 8-14. [CrossRef] [PubMed]

12. Sears, B. Anti-inflammatory Diets. J. Am. Coll. Nutr. 2015, 34, 14-21. [CrossRef]

13. Romanucci, V.; D’Alonzo, D.; Guaragna, A.; Di Marino, C.; Davinelli, S.; Scapagnini, G.; Di Fabio, G.; Zarrelli, A. Bioactive Compounds of Aristotelia chilensis Stuntz and their Pharmacological Effects. Curr. Pharm. Biotechnol. 2016, 17, 513-523. [CrossRef] [PubMed]

14. Vázquez-Espinosa, M.; Espada-Bellido, E.; González de Peredo, A.V.; Ferreiro-González, M.; Carrera, C.; Palma, M.; Barroso, C.G.; Barbero, G.F. Optimization of Microwave-Assisted Extraction for the Recovery of Bioactive Compounds from the Chilean Superfruit (Aristoteliachilensis (Mol.) Stuntz). Agronomy 2018, 8, 240. [CrossRef]

15. Lucas-Gonzalez, R.; Navarro-Coves, S.; Pérez-Álvarez, J.A.; Fernández-López, J.; Muñoz, L.A.; Viuda-Martos, M. Assessment of polyphenolic profile stability and changes in the antioxidant potential ofmaqui berry (Aristoteliachilensis (Molina) Stuntz) during in vitro gastrointestinal digestion. Ind. Crops Prod. 2016, 94, 774-782. [CrossRef]

16. Misle, E.; Garrido, E.; Contardo, H.; Gonzalez, W. Maqui [Aristoteliachilensis (Mol.) Stuntz]-the Amazing Chilean Tree: A Review. J. Agric. Sci. Technol. 2011, 1, 473-482.

17. Zamora-Gasga, V.M.; Bello-Perez, L.A.; Ortiz-Basurto, R.I.; Tovar, J.; Sayago-Ayerdi, S.G. Granola bars prepared with Agave tequila ingredients: Chemical composition and in vitro starch hydrolysis. LWT Food Sci. Technol. 2014, 56, 309-314. [CrossRef]

18. Leal-Diaz, A.M.; Santos-Zea, L.; Martinez-Escobedo, H.C.; Guajardo-Flores, D.; Gutierrez-Uribe, J.A.; Serna-Saldivar, S.O. Effect of Agave americana and Agave salmiana Ripeness on Saponin Content from Aguamiel (Agave Sap). J. Agric. Food Chem. 2015, 63, 3924-3930. [CrossRef]

19. Muniz-Marquez, D.B.; Contreras, J.C.C.; Rodriguez, R.; Mussatto, S.I.; Wong-Paz, J.E.; Aguilar, T.C.N. Influence of thermal effect on sugar composition of Mexican Agave syrup. CyTA J. Food 2015, 13, 607-612. [CrossRef]

20. Espinosa-Andrews, H.; Urias-Silvas, J.E. Thermal properties of agave fructans (Agave tequilana Weber var. Azul). Carbohydr. Polym. 2012, 87, 2671-2676. [CrossRef]

21. Phillips, K.M.; Carlsen, M.H.; Blomhoff, R. Total Antioxidant Content of Alternatives to Rafined Sugar. J. Am. Diet. Assoc. 2009, 109, 64-71. [CrossRef] [PubMed]

22. Pintor-Jardines, A.; Arjona-Roman, J.L.; Totosaus-Sanchez, A.; Severiano-Perez, P.; Gonzalez-Gonzalez, L.R.; Escalona-Buendia, H.B. The influence of agave fructans on thermal properties of low-fat, and low-fat and sugar ice cream. LTW Food Sci. Technol. 2018, 93, 679-685. [CrossRef]

23. Ellis, A.L.; Mills, T.B.; Norton, I.T.; Norton-Welch, A.B. The effect of sugars on agar fluid gels and the stabilisation of their foams. Food Hydrocol. 2019, 87, 371-381. [CrossRef]

24. Sugar Reduction. Sugar Reduction Achieving the 20\%; Public Health England Publications Gateway Number 2016677; Public Health England: London, UK, 2017. 
25. Różyło, R.; Wójcik, M.; Dziki, D.; Biernacka, B.; Cacak-Pietrzak, G.; Gawłowski, S.; Zdybel, A. Freeze-dried elderberry and chokeberry as natural colorants for gluten-free wafer sheets. Int. Agrophys. 2019, 33, 217-225. [CrossRef]

26. Różyło, R.; Wójcik, M.; Biernacka, B.; Dziki, D. Gluten-free crispbread with freeze-dried blackberry: Quality and mineral composition. CYTA J. Food 2019, 17, 841-849. [CrossRef]

27. Szczesniak, A.S.; Bertrand, J.H. Application of the General Foods Texturometer to Specific Food Products. J. Texture Stud. 1975, 6, 117-138. [CrossRef]

28. Lim, H.S.; Park, S.H.; Ghafoor, K.; Hwang, S.Y.; Park, J. Quality and antioxidant property of bread containing turmeric (Curcuma longa L.) cultivated in South Korea. Food Chem. 2011, 112, 1577-1582.

29. Houghton, P.J.; Raman, A. Methods for extraction and sample clean-up. In Laboratory Handbook for the Fractionation of Natural Extracts; Springer: Boston, MA, USA, 1998; pp. 22-53.

30. Hashim, N.; Shaari, A.R.; Mamat, A.S.; Ahmad, S. Effect of Differences Methanol Concentration and Extraction Time on the Antioxidant Capacity, Phenolics Content and Bioactive Constituents of OrthosiphonStamineus Extracts. MATEC Web Conf. 2016, 78, 01004. [CrossRef]

31. Singleton, V.L.; Rossi, J. Colorimetry of Total Phenolics with Phosphomolybdic. Am. J. Enol. Vitic. 1965, 6, 144-158.

32. Re, R.; Pellegrini, N.; Proteggente, A.; Pannala, A.; Yang, M.; Rice-Evans, C. Antioxidant Activity Applying an Improved ABTS Radical Cation Decolorization Assay. Free Rad. Biol. Med. 1999, 26, 1231-1237. [CrossRef]

33. Brand-Williams, W.; Cuvelier, M.E.; Berset, C. Use of a Free Radical Method to Evaluate Antioxidant Activity. LWT Food Sci. Technol. 1995, 28, 25-30. [CrossRef]

34. Oyaizu, M. Studies on products of browning reaction-Antioxidative activities of products of browning reaction prepared from glucosamine. Jpn. J. Nutr. 1986, 44, 307-315. [CrossRef]

35. Guo, J.T.; Lee, H.L.; Chiang, S.H.; Lin, F.I.; Chang, C.Y. Antioxidant Properties of the Extracts from Different Parts of Broccoli in Taiwan. J. Food Drug Anal. 2001, 9, 96-101.

36. Casati, C.B.; Baeza, R.; Sánchez, V. Physicochemical properties and bioactive compounds content in encapsulated freeze-dried powders obtained from blueberry, elderberry, blackcurrant and maqui berry. J. Berry Res. 2019, 9, 1-17. [CrossRef]

37. GarridoMakinistian, F.; Sette, P.; Gallo, L.; Bucalá, V.; Salvatori, D. Optimized aqueous extracts of maqui (Aristoteliachilensis) suitable for powder production. J. Food Sci. Technol. 2019, 56, 3553-3560. [CrossRef]

38. Garrido Makinistian, F.; Gallo, L.; Sette, P.; Salvatori, D.; Bucalá, V. Nutraceutical tablets from maqui berry (Aristoteliachilensis) spray-dried powders with high antioxidant levels. Dry. Technol. 2020, 38, 1231-1242. [CrossRef]

39. Fredes, C.; Montenergo, G.; Zoffoli, J.P.; Gómez, M.; Paz, R. Polyphenol Content and Antioxidant Activity of Maqui (Aristoteliachilensis [Molina] Stuntz) During Fruit Development and Maturation in Central Chile. Chil. J. Agric. Res. 2012, 72, 582-589. [CrossRef]

40. Romero-González, J.; Shun Ah-Hen, K.; Lemus-Mondaca, R.; Muñoz-Fariña, O. Total phenolics, anthocyanin profile and antioxidant activity of maqui, Aristoteliachilensis (Mol.) Stuntz, berries extract in freeze-dried polysaccharides microcapsules. Food Chem. 2020, 313, 126115. [CrossRef]

41. Leyrer, J.; Hunter, R.; Rubilar, M.; Pavez, B.; Morales, E.; Torres, S. Development of dye-sensitized solar cells based on naturally extracted dye from the maqui berry (Aristoteliachilensis). Optic. Mater. 2016, 60, 411-417. [CrossRef]

42. Gironés-Vilaplana, A.; Valentão, P.; Moreno, D.A.; Ferreres, F.; García-Viguera, C.; Andrade, P.B. New beverages of lemon juice enriched with the exotic berries maqui, açaí, and blackthorn: Bioactive components and in vitro biological properties. J. Agric. Food Chem. 2012, 60, 6571-6580. [CrossRef]

43. Gironés-Vilaplana, A.; Huertas, J.P.; Moreno, D.A.; Periago, P.M.; García-Viguera, C. Quality and microbial safety evaluation of new isotonic beverages upon thermal treatments. Food Chem. 2016, 194, 455-462. [CrossRef] [PubMed]

44. Leyrer, J.; Rubilar, M.; Morales, E.; Pavez, B.; Leal, E.; Hunter, R. Factor Optimization in the Manufacturing Process of Dye-Sensitized Solar Cells Based on Naturally Extracted Dye from a Maqui and Blackberry Mixture (Aristotelia chilensis and Rubus glaucus). J. Electron. Mater. 2018, 47, 6136-6143. [CrossRef]

45. Rein, M.J. Copigmentation Reactions and Color Stability of Berry Anthocyanins. Ph.D. Thesis, University of Helsinki, Helsinki, Finland, 2005; p. 87. 
46. Pang, Z.; Deeth, H.; Sopade, P.; Sharma, R.; Bansal, N. Rheology, texture and microstructure of gelatin gels with and without milk proteins. Food Hydrocol. 2014, 35, 484-493. [CrossRef]

47. Torres, C.A.; Romero, L.A.; Diaz, R.I. Quality and sensory attributes of apple and quince leathers made without preservatives and with enhanced antioxidant activity. Food Sci. Technol. 2014, 62, 996-1003. [CrossRef]

48. Freses, C.; Paz, R. The powerful colour of the maqui (Aristoteliachilensis [Mol.] Stuntz) fruit. J. Berry Res. 2014, 4, 175-182. [CrossRef]

Publisher's Note: MDPI stays neutral with regard to jurisdictional claims in published maps and institutional affiliations.

(C) 2020 by the authors. Licensee MDPI, Basel, Switzerland. This article is an open access article distributed under the terms and conditions of the Creative Commons Attribution (CC BY) license (http://creativecommons.org/licenses/by/4.0/). 